\title{
Revitalisasi Tirtomoyo Sebagai Sport And Wellness Center Di Surakarta dengan Pendekatan Konsep Arsitektur Dekonstruksi
}

\author{
Dhani Mutiari , Intan Mentari Putri Gesyari \\ Program Studi Arsitektur Fakultas Teknik - Universitas Muhammadiyah Surakarta \\ Email: dhani.mutiari@ums.ac.id
}

\begin{abstract}
ABSTRAK
Revitalisasi merupakan upaya untuk menghidupkan kembali suatu daerah, kawasan atau bangunan agar dapat berfungsi kembali. Tirtomoyo merupakan fasilitas olah raga berenang pertama yang ada di Kota Surakarta. Fasilitas ini dahulu digunakan untuk PON pertama kali pada taun 1948 dan belum pernah diperbarui hingga sekarang. Seiring berjalannya waktu muncullah fasilitas-fasilitas olahraga berenang yang lebih menarik hingga Tirtomoyopun tertinggal karena tidak terurus dan sempat mangkrak selama beberapa tahun. Nilai sejarah pada Tirtomoyo sebagai tempat diadakan PON yang pertama menjadi motivasi untuk di revitalisasi. Permasalahannya adalah bagaimanakah konsep bangunan yang mampu mempertahankan Tirtomoyo sebagai kenangan masa lalu tetapi tetap dapat diterima untuk konsisi masa kini dan yang akan datang. Perencanaan wahana olahraga, rekreasi, dan sarana edukasi untuk masyarakat di sekitar Kota Surakarta menjadi pilihan sebagai upaya menghidupkan kembali kolam renang di Tirtomoyo. Konsep desain dilakukan dengan menggabungkan bangunan lama dengan bangunan baru menggunakan penerapan trace of memory dan adaptive re-use hingga menghasilkan bangunan yang tetap mempertahankan kenangan masa lalu tirtomoyo dengan fungsi dan nuansa kekinian. Tirtomoyo Sport And Wellness Center Surakarta, selain tempat olah raga juga menjadi tempat untuk membuat masyarakat menjadi baik.
\end{abstract}

Kata kunci: adaptive re-use, edukasi, kolam renang, rekreasi, trace of memory Inggris.

\begin{abstract}
Revitalization is an effort to revive an area, area or building so that it can function again. Tirtomoyo is the first swimming sport facility in the city of Surakarta. This facility was used for PON for the first time in 1948 and has not been updated until now. Over time came the more attractive swimming sport facilities until Tirtomoyopun was left behind because it was neglected and had been stalled for several years. The historical value of Tirtomoyo as the first PON venue was motivated to be revitalized. The problem is how the concept of a building that is able to maintain Tirtomoyo as a memory of the past but still acceptable for present and future concessions. Planning a sports vehicle, recreation, and educational facilities for the community around the city of Surakarta is an option as an effort to revive the swimming pool in Tirtomoyo. The design concept is carried out by combining old buildings with new buildings using the application of trace of memory and adaptive re-use to produce buildings that still retain tirtomoyo's past memories with the functions and nuances of the present. Tirtomoyo Sport and Wellness Center Surakarta, in addition to sports venues, is also a place to make the community better.
\end{abstract}

Keywords: adaptive re-use, education, swimming pool, recreation, trace of memory UK 


\section{PENDAHULUAN}

\subsection{Latar Belakang}

Saat ini Kolam Renang Tirtomoyo Jebres merupakan ruang publik yang berfungsi sebagai tempat olahraga renang di Kota Surakarta yang dikelola oleh PDAM (Perusahaan Daerah Air Minum). Seiring berjalannya waktu, banyak tempat olahraga renang baru yang bermunculan di beberapa tempat, bahkan hotel-hotel di Solo menyedialkan fasilitas renang yang dibuka untuk umum. Kondisi ini menyebabkan Tirtomoyo sepi pengunjung bahkan sempat tutup selama beberapa waktu. Sebenarnya pada tahun 2013 lokasi Tirtomoyo akan di demolisi dan di bangun dengan hotel tetapi mengingat nilai sejarah yang terdapat di lokasi tersebut maka rencana tersebut ditolah oleh Pemerintah Daerah. Hingga Januari 2018 Tirtomoyo Jebres masih beroperasional, tetapi fasilitas yang tersedia sangat memrihatinkan dan tidak layak digunakan, sehingga kurang menarik minat pengunjung.

Revitalisasi atau upaya menghidupkan kembali suatu daerah, wilayah atau bangunan agar dapat berfungsi lebih baik dan ramai dikunjungi masyarakat adalah langkah yang diusulkan supaya bangunan lama yang memiliki nilai sejarah tidak mangkrak. Selain kolam renang yang telah ada juga perlu dipikirkan kegiatan lain yang dapat mendukung fungsi utamanya. Penelitian yang dipublikasian di Neurology pada pertengahan tahun 1990 hingga 2000, menunjukkan adanya peningkatan stroke terhadap orang dewasa yang berusia 20 hingga 45 tahun. Melihat dari hasil penelitian ini maka dapat disimpulkan bahwa hal ini diakibatkan oleh kesalahan pilihan dalam lifestyle di usia yang relatif masih muda. Menurut SFU (2014) Wellness adalah istilah yang digunakan sebagai sebuah proses untuk menyadari dan membuat pilihan menuju kehidupan yang sehat dan memuaskan. Kesehatan lebih dari sekedar bebas dari penyakit, tetapi juga proses perubahan dan pertumbuhan yang dinamis. Oleh karena itu, penting bagi setiap orang untuk mencapai kesehatan optimal guna menundukkan stres, mengurangi risiko penyakit dan memastikan interaksi positif menuju kehidupan yang sehat dan lebih baik [1].

Revitalisasi Tirtomoyo sebagai tempat olah raga dan Wellness Center Di Surakarta, selain menyediakan kolam renang sebagai olahraga utama yang ditawarkan, juga terdapat wellness center untuk menunjang pola hidup sehat dan memenuhi kesejahteraan tubuh masyarakat.

\subsection{Permasalahan}

Tirtomoyo perlu untuk dihidupkan kembali fungsi utama dan pendukungnya agar dapat lebih menarik untuk kondisi sekarang dan masa yang akan datang. Permasalahannya adalah :
a. a.Bagaimana merevitalisasi Tirtomoyo sebagai tempat olah raga sekaligus Wellness Center di Surakarta?
b. Fasilitas apa saja yang dapat mendukung untuk kegiatan olah raga penunjang kesejahteraan tubuh penggunanya?
c. Bagaimanakah konsep bentuk yang dapat diaplikasikan agar Tirtomoyo dapat dikenang sebagai bagian dari sejarah masa lalu tetapi dapat mengukuti perkembangan masa sekarang.

\section{METODOLOGI}

\subsection{Olah Raga Renang}

Menurut Undang-Undang Republik Indonesia Nomor3 Tahun 2005 Tentang Sistem Keolahragaan Nasional, olahraga adalah kegiatan yang sistematis untuk mendorong, membina, serta mengembangkan potensi jasmani, rohani, dan sosial.Olahraga dapat dikatakan sebagai kesibukan yang bertujuan untuk menjaga kesehatan seseorang [2]. Selain dapat mereduksi stres, olahraga juga dapat menggiatkan metabolisme dalam tubuh dan membantu melindungi dari penyakit seperti stroke, jantung, diabetes, tekanan darah tinggi, osteoporosis, nyeri punggung dan lainnya.[3]

Dalam KBBI dijelaskan bahwa renang adalah kegiatan menggerakkan badan secara melintas (mengapung atau menyelam) di air dengan menggunakan kaki, tangan, sirip, ekor, dan 
sebagainya.Kegiatan berenang dapat difungsikan sebagai sarana olahraga, rekreasi, ataupun mencari ikan, mutiara atau hewan air lainnya yang dilakukan di sungai, danau, laut dan kolam renang. Berenang dapat dilakukan oleh siapa saja dari berbagai usia dan kalangan masyarakat. Kolam renang adalah suatu konstruksi buatan yang dirancang untuk diisi dengan air dan digunakan untuk berenang, menyelam, atau aktivitas air lainnya. Kolam renang umum biasanya merupakan bagian dari pusat kebugaran jasmani atau taman rekreasi, dengan fasilitas-fasilitas lainnya meliputi sauna, lapangan olahraga renang, serta rumah makan.[4]

\subsection{Preservasi dan Konservasi pada Arsitektur}

Kata konservasi berasal dari kata conservation yang merupakan gabungan dari kata con (together) dan servare (keep). Konservasi dapat diartikan menjadi upaya pelestarian terhadap yang sudah kita miliki secara bijaksana agar dapat difungsikan dengan baik. Terdapat 2 istilah yang menjadi prinsip dalam konsep pelestarian bangunan, yaitu Aktif dan pasif. Konsep pelestarian secara pasif kita kenal dengan preservasi sedangkan secara aktif kita kenal dengan istilah konservasi, tetapi baik preservasi maupun konservasi lebih dominan pengembalian bangunan pada bentuk lamanya. Secara lebih detil terdapat 6 katagori di dalam istilah preservasi dan konservasi yaitu :

a. Restorasi

Mengembalikan bentuk fisik suatu bangunan pada kondisi sebelumnya dengan menghilangkan atau menambahkan komponen eksisting dengan material baru.

b. Preservasi

Pemeliharaan bangunan dan lingkungan yang mempertahankan keadaan bentukan fisik suatu tempat sesuai kondisi eksisting untuk memperlambat proses kerusakan.

c. Rekonstruksi

Pemugaran untuk memperbaiki dan membangun kembali suatu bangunan dan lingkungan yang hancur diakibatkan oleh bencana alam dan lainnya.

d. Konsolidasi

Pemugaran yang difokuskan pada perkuatan suatu struktur bangunan yang rusak agar persyaratan teknis dapat terpenuhi.

e. Revitalisasi

Pemugaran yang difokuskan kepada nilai ekonomi, sosial, dan budaya dengan pemanfaatan bangunan dan lingkungan dan mencegah hilangnya aset kota yang bernilai sejarah.

f. Adaptasi

Upaya pemugaran suatu tempat agar dapat digunakan untuk fungsi yang sesuai. [5]

\subsection{Arsitektur Dekonstruksi}

Terdapat beberapa konsep desain yang menggabungkan antara unsur baru dan lama seperti yang sudah dijelaskan pada sub bab 2.2. Selain konsep diatas penggabungan ini juga diimplementasikan pada beberapa karya arsitektur dekonstruksi. Arsitektur Dekonstruksi adalah pendekatan desain bangunan dengan usaha percobaan melihat arsitektur dari sisi yang berbeda. Pendekatan ini muncul sekitar tahun 1970 [6]. Langgam arsitektur ini merupakan jawaban dari perasaan jenuh atas kemonotonan suatu bentuk bangunan. Beberapa arsitek dunia yang menghasilkan karya arsitektur dekonstruksi adalah Daniel Libeskind, Frank O. Gehry, Zaha Hadid, IM. Pei dan Bernard Tschumi.

Trace of memory adalah konsep yang diusung oleh Bernard Tsumi, implementasi dari konsep ini adalah peninggalan masa lalu sebagai memory yang melekat dan disandingkan dengan bangunan baru serta bentukan yang akan datang atau futuristic [7]. Daniel Libeskind mencoba untuk membuat bangunan baru diantara bangunan lama dengan bentuk yang kontras. Konsep ini juga digunakan oleh IM Pei yang membuat perpustakaan dengan bentuk piramida kristal di kawasan kota lama. 

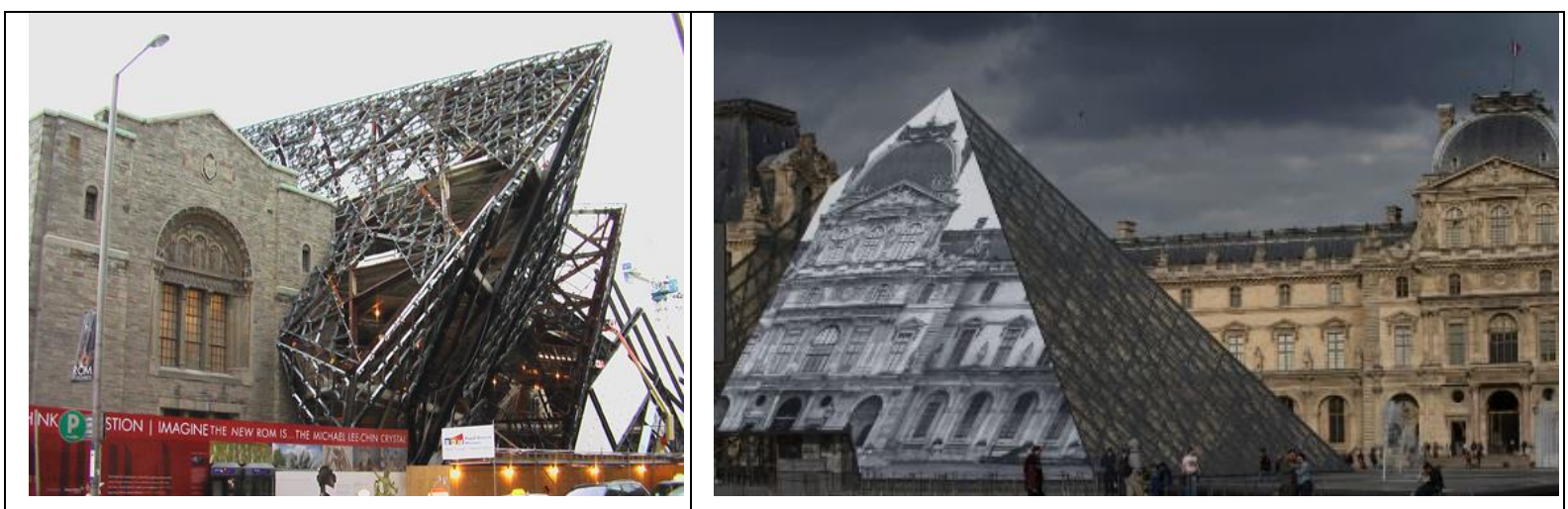

Gambar 1 Royal Ontario Museum Karya Daniel Libeskind dan Perpustakaan karya IM.Pei Sumber : https://www.archdaily.com/791888/swimming-pool-allmendli-illiz-architektur [8]

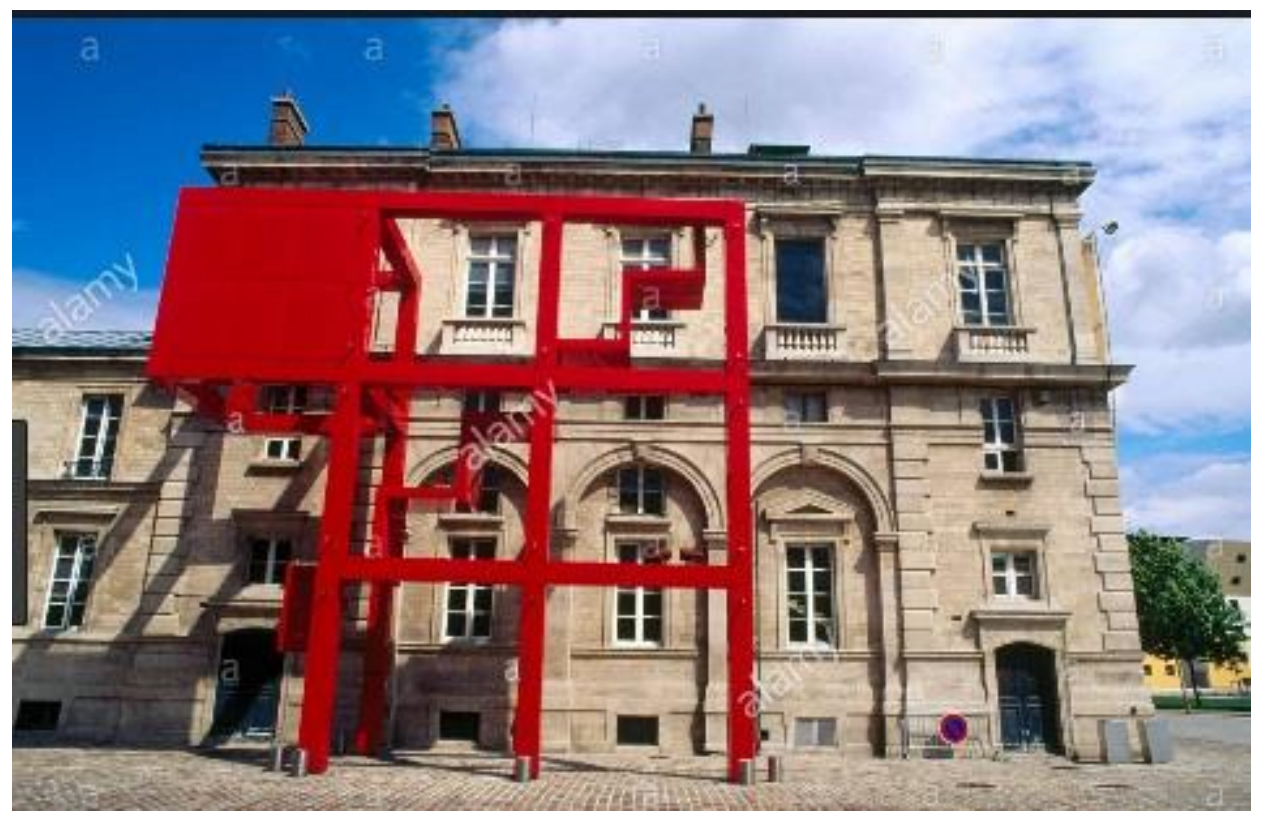

Gambar 2 Karya Bernhard Tsumi

Sumber : https://www.hawkinsbrown.com/projects/city-of-london-freemens-schoolswimming-pool [9]

\subsection{Model Renovasi pada Arsitektur Kolam Renang}

Freemen's School Swimming Pool merupakan karya dari arsitek Roger Hawkins dan Russell Brown yang membentuk firma arsitektur Hwakins\Brown. Freemen's School Swimming Pool berlokasi di Surrey, United Kingdom seluas $1750 \mathrm{~m} 2$ yang dibangun tahun 2017. Bangunan ini menggantikan gedung kolam renang milik sekolah yang sudah terbakar di tahun 2014. Kolam renang yang baru menggunakan kontruksi kayu dan metode offset fabrication. Tersedia enam lajur lintasan renang sepanjang 25 meter untuk tujuan edukasi dan event tertentu.[10] 


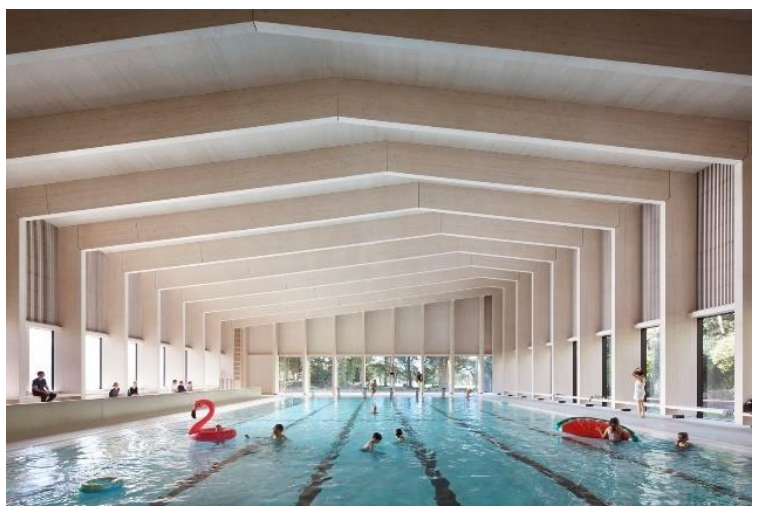

Gambar 3 Freemen's School Swimming Pool

Sumber: https://libeskind.com/work/royal-ontario-museum/ [10]
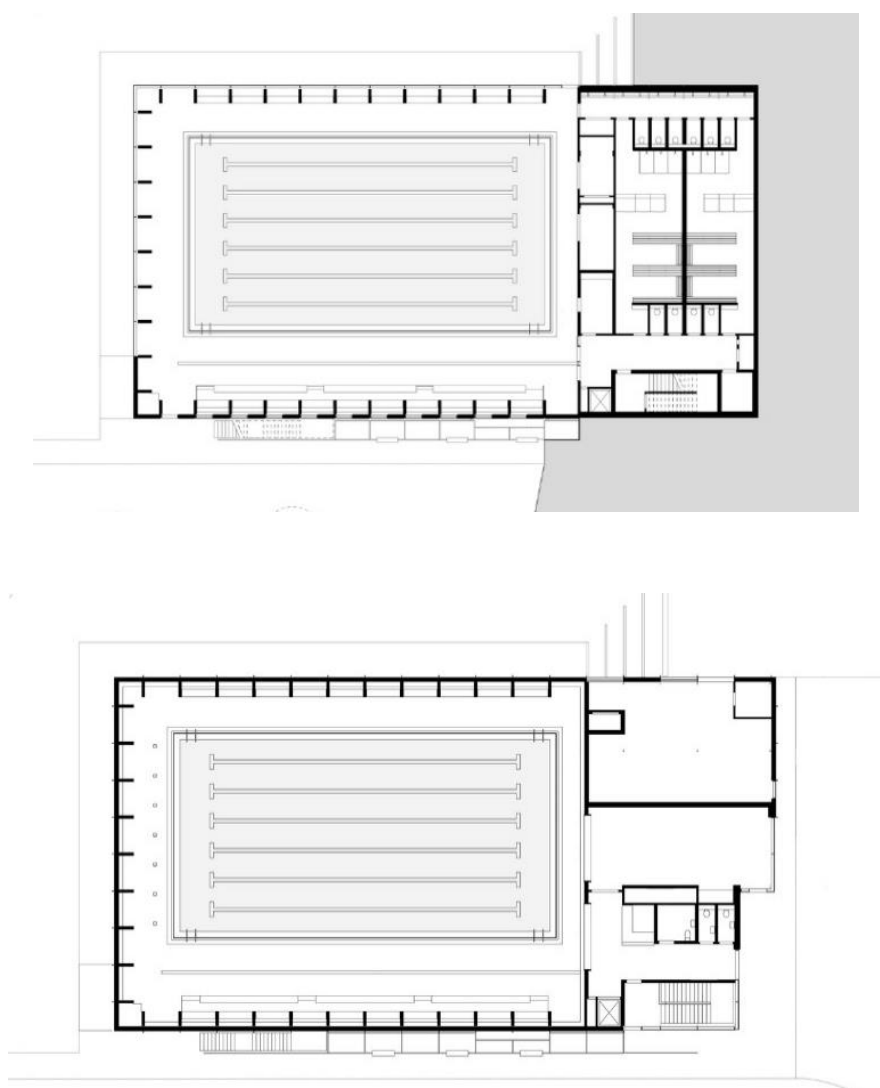

\section{Gambar 4 Ground Floor Plan dan Upper Ground Floor Plan Freemen's School Swimming Pool}

Sumber: https://libeskind.com/work/royal-ontario-museum/ [10]

Selain Freemen's School Swimming Pool juga terdapat Swimming Pool Allmendli merupakan karya dari firma arsitektur Illiz Architektur, berlokasi di Erlenbach, Switzerland seluas $1131 \mathrm{~m} 2$ yang dibangun tahun 2016. Bangunan ini dibangun dibekas tempat perlindungan pasukan penyelamat yang sudah tidak digunakan. Terletak di tepi kampus Erlenbach dekat lapangan olahraga yang sudah hilang tertutupi bukit yang ditumbuh pepohonan selama bertahun-tahun, hanya terlihat dua pintu masuk dari lereng bukit. Kolam renang ini dibangun dengan tujuan edukasi bagi pelajar dan para pemula. Beberapa fasilitas dari gedung yang lama masih tetap utuh. Lantai 
pelat beton di ruang bawah tanah ditutupi dengan lapisan pelindung, sementara pemandu kabel dan saluran pipa diperlihatkan.[1]

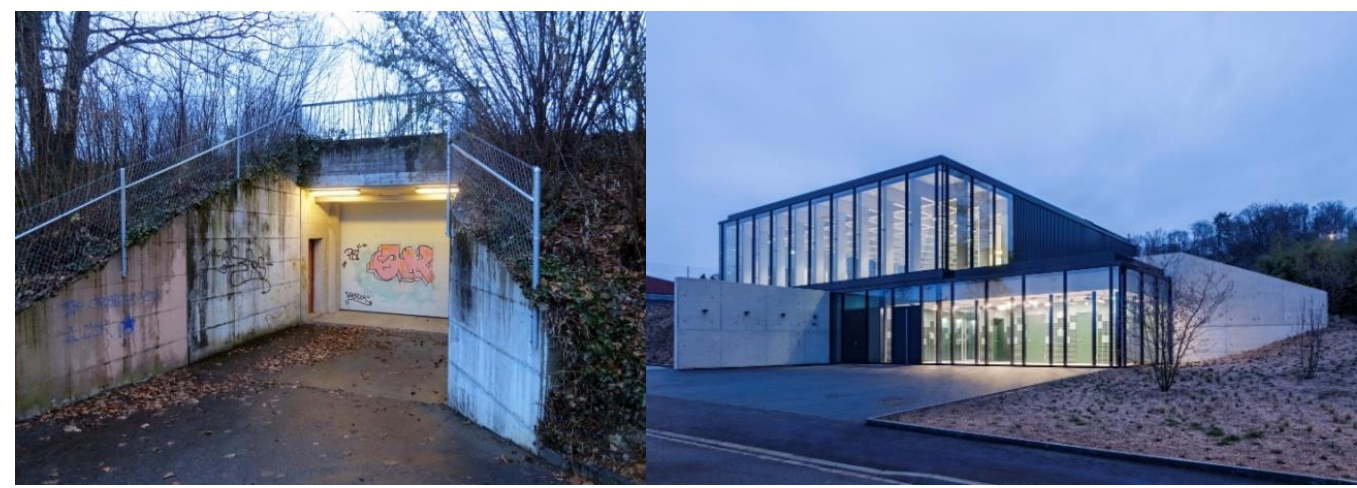

Gambar 5 Kondisi Eksisting Swimming Pool Allmendli

Sumber: https://libeskind.com/work/royal-ontario-museum/ [10].
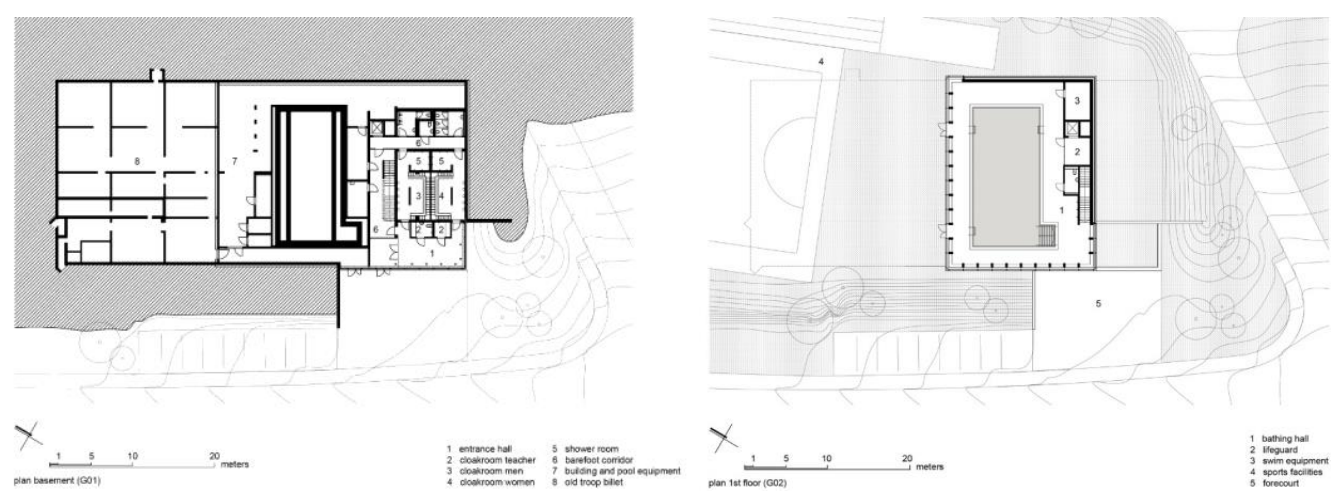

Gambar 6 Basement dan First Floor Swimming Pool Allmendli

Sumber: https://libeskind.com/work/royal-ontario-museum/ [10]

Dari kedua contoh desain kolam renang diatas maka dapat dirangkum sebagai berikut :

Tabel 1 Perbandingan ke dua swimming pool

\begin{tabular}{c|c|c}
\hline \multirow{2}{*}{ Aspek } & \multicolumn{2}{|c}{ Bangunan } \\
\cline { 2 - 3 } & Freemen's School Swimming Pool & Swimming Pool Allmendli \\
\hline Tahun & 2017 & 2016 \\
\hline Luas & $1750 \mathrm{~m}^{2}$ & $1131 \mathrm{~m}^{2}$ \\
\hline Arsitek & Hwakins 1 Brown & Illiz Architektur \\
\hline Lokasi & Surrey, United Kingdom & Erlenbach, Switzerland \\
\hline Fungsi & $\begin{array}{l}\text { Tempat edukasi olahraga renangbagi } \\
\text { pelajar Freemen's School dan } \\
\text { penyelenggaraan event }\end{array}$ & $\begin{array}{l}\text { Tempat edukasi olahraga renang } \\
\text { bagi pelajar sekolah di dekat lokasi } \\
\text { site dan perenang pemula }\end{array}$ \\
\hline
\end{tabular}




\begin{tabular}{c|l|l}
\hline \multirow{2}{*}{ Aspek } & \multicolumn{2}{c}{ Bangunan } \\
\cline { 2 - 3 } & \multicolumn{1}{c}{ Freemen's School Swimming Pool } & \multicolumn{1}{c}{ Swimming Pool Allmendli } \\
\hline \multirow{3}{*}{ Konsep Konservasi } & $\begin{array}{l}\text { Restorasi fungsi dengan proses } \\
\text { pengelolaan bangunan menyesuaikan } \\
\text { fungsi asalnya merakit kembali dengan } \\
\text { material baru. }\end{array}$ & $\begin{array}{l}\text { Adaptive rengan } \\
\text { mengalihkan fungsi lama (tempat } \\
\text { perlindungan) menjadi fungsi baru } \\
\text { (kolam renang) }\end{array}$ \\
\hline
\end{tabular}

Sumber: Analisis Penulis, 2018.

\subsection{Design Method}

Tirtomoyo sebagai bangunan lama yang dibangun untuk pelaksanaan PON pertama pada tahun 1948 di Surakarta. Keberadaannya memiliki nilai sejarah masyarakat Kota Surakarta, sehingga perubahan atau pengembangan baru pada bangunan ini diharapkan masih menyisakan memori masa lalu dan dipadukan dengan unsur kekinian. Tidak hanya dari segi fungsi tetapi juga dari bentuk tampilan bangunan. Dengan pertimbangan diatas maka metode desain yang digunakan adalah :

1. Revitalisasi Bangunan

2. Mempertahankan Kolam Renang lama dan mengembangkan dengan fungsi-fungsi baru yang mendukung keberadaan dari Tirtomoyo di masa lalu. Adaptive re use dilakukan sebagai langkah untuk merubah fungsi kolam renang sebagai tempat olah raga kompetisi menjadi rekreasi. Selain itu juga pengembangan olah-raga lain dan fungsi wellnes center.

3. Penggabungan antara bangunan lama dan baru dengan menggunakan konsep dekonstruksi yang telah digunakan sebelumnya oleh Bernhard Tsumi, Daniel Libeskind dan IM Pei. Konsep yang digunakan adalah menonjolkan perbedaan secara kontras antara bangunan lama dan baru.

\section{HASIL DAN PEMBAHASAN}

\subsection{Existing dan Evaluasi Purna}

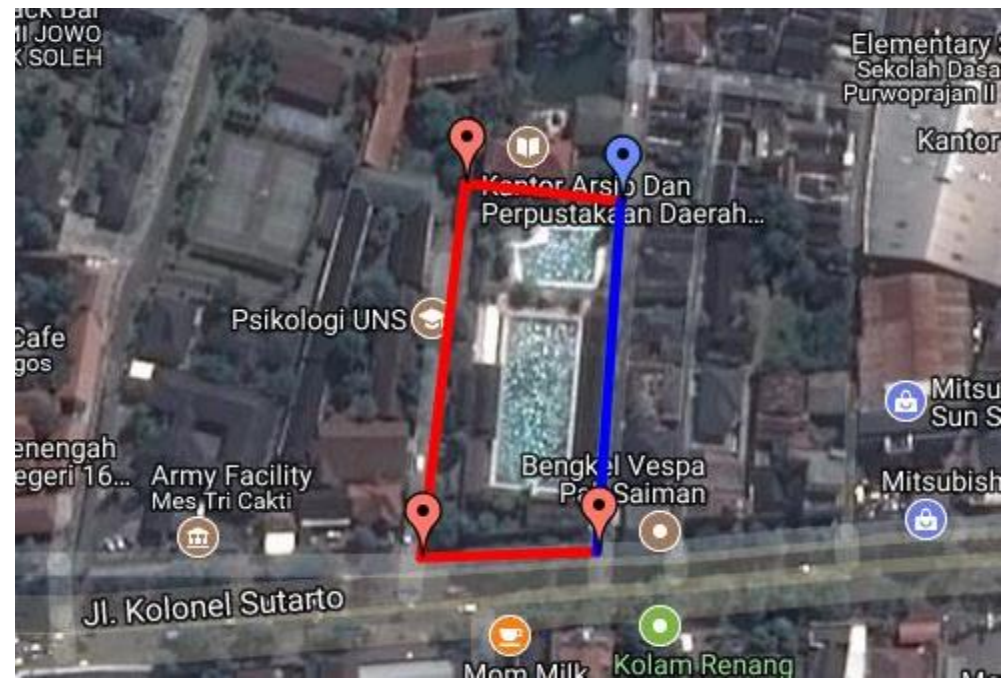

Gambar 7 Lokasi dan Existing Kolam renang Tirtomoyo Sumber : http:// geogle map. [11] 


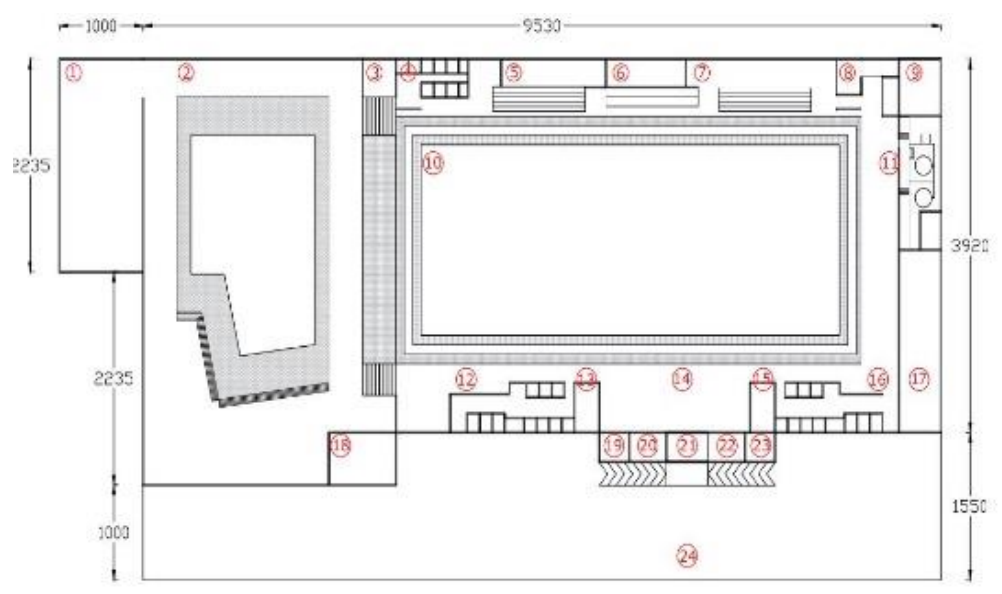

Gambar 8 Siteplan Kolam Renang

1. Tanah kosong

2. Kolam renang anak

3. Kantin timur

4. Toilet

5. Gudang klub renang 1

6. Gudang klub renang 2

7. Gudang

8. Toilet
9. Pos warga

10. Kolam renang dewasa

11. Ruang pengolahan air

12. Ruang bilas wanita

13. Ruang rapat

14. Ruang latihan

15. Gudang

16. Ruang bilas pria
17. Tanah kosong

18. Kantin barat

19. Musholla

20. Kantor

21. Entrance

22. Loket

23. Ruang karyawan

24. Area parkir

Kolam renang hanya tersedia dua jenis yaitu untuk anak-anak dan dewasa. Kolam renang dilapisi dengan keramik di segala sisi. Area di sekitar kolam renang pun juga tertutupi keramik berukuran 20 x $10 \mathrm{~cm}$. Pada kolam renang dewasa disediakan tangga yang terbuat dari aluminium, sedangkan kolam renang anak berupa anak tangga didalam kolam yang dilapisi keramik pada sisi barat kolam. Pada kolam renang anak, keramik pada pinggir kolam renang yang sudah terlepas.Keramik yang sudah terlepas tersebut sudah disiasati dengan semen. Sedangkan keramik di dalam kolam renang masih terpasang rapi.
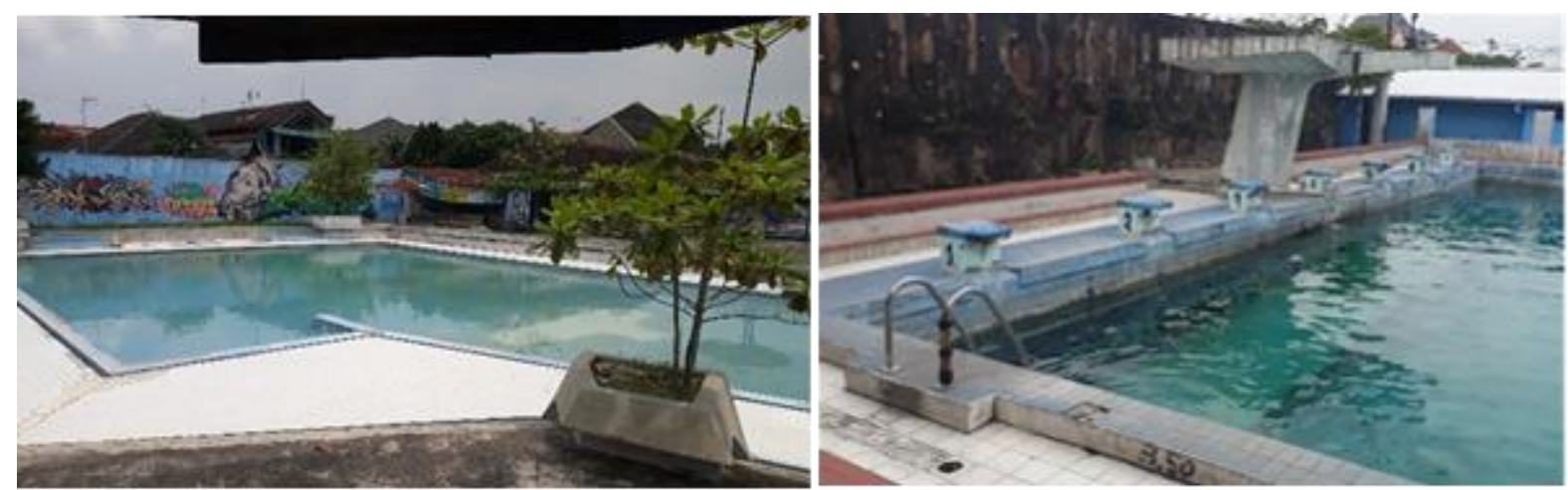

Gambar 9 Kolam renang Anak dan Kolam Renang Dewasa

Sumber : Dokumentasi Penulis, 2018

Selain kolam renang di Tirtomoyo juga terdapat ruang pendukung lainnya seperti ruang bilas, toilet, ruang duduk pengunjung atau tribun dan ruang untuk latihan. Ruang ruang ini secara exixting masih lengkap tetapi kondisinya sudah tidak terawat lagi. 


\subsection{Konsep dan Desain}

Dengan adanya nilai sejarah yang akan dipertahankan pada rancangan bangunan maka dilakukan penerapan trace of memory dengan konsep menyatukan bangunan lama dengan bangunan baru menggunakan prinsip arsitektur dekonstruksi dan konsep konservasi adaptive re-use. Seperti bangunan Royal Ontario Museum karya Daniel Libeskind, Walt Disney Concert Hall karya Frank Gehry, serta Florida International University School of Architecture karya Bernard Tschumi. Sehingga Tirtomoyo Sport and Wellness Center dapat mempertahankan nilai sejarah dan menarik minat masyarakat dengan desain baru.

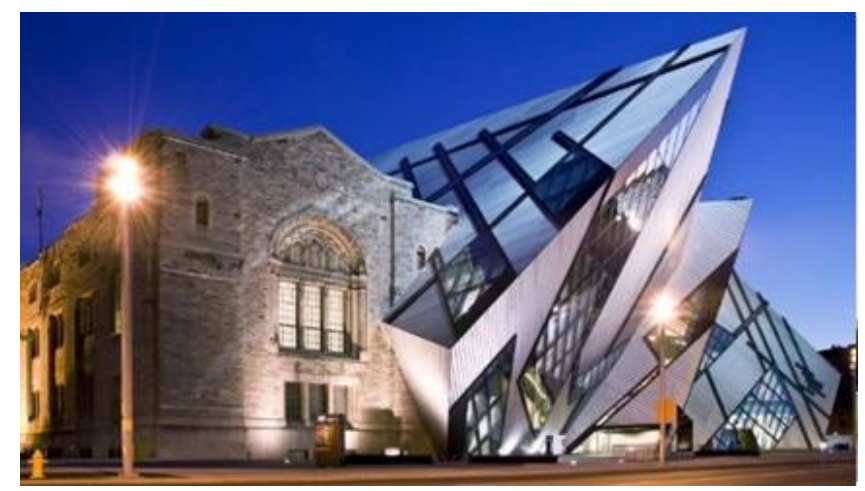

Gambar 10: Royal Ontario Museum

Sumber : https://www.archdaily.com/791888/swimming-pool-allmendli-illiz-architektur [8]

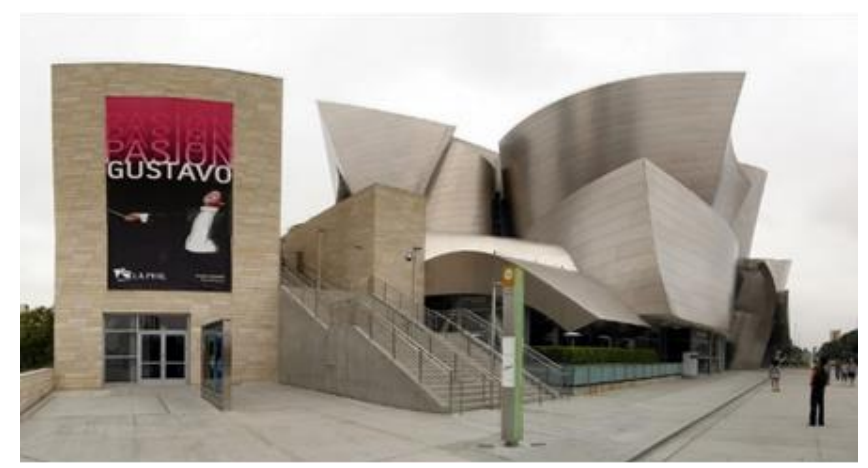

Gambar 11: Walt Disney Concert Hall

Sumber : https://libeskind.com/work/royal-ontario-museum [10]

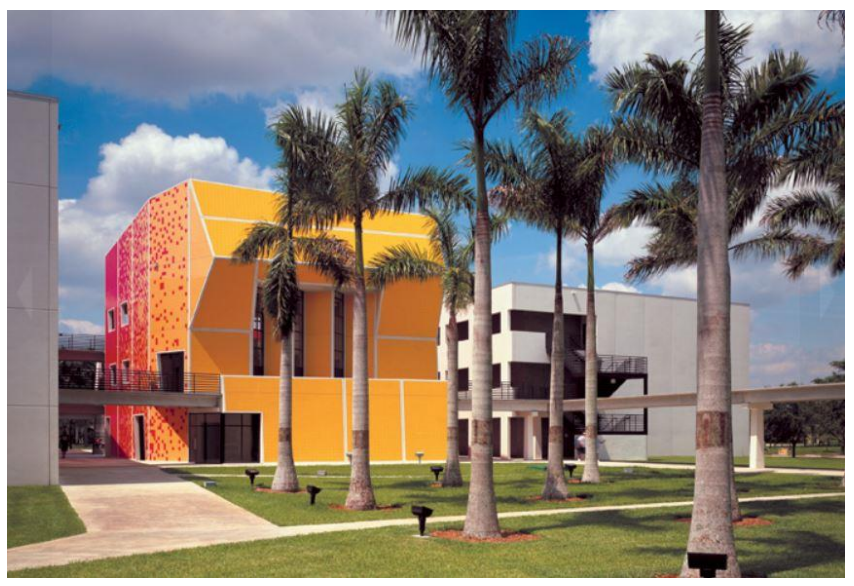

Gambar 112: School of Architecture, FIU

Sumber: https://www.archdaily.com/791888/swimming-pool-allmendli-illiz-architektur [8]. 
Zonifikasi ruang di Tirtomoyo Sport and Wellness Center Surakarta dalam bentuk diagram vertical adalah sebagai berikut:

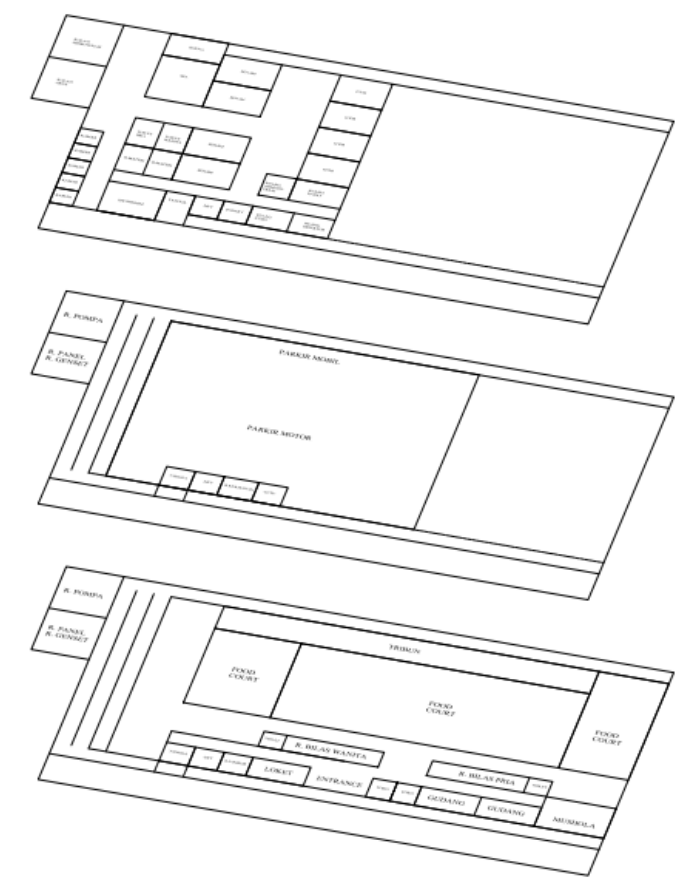

\section{Lantai 3}

Wellness dengan fasilitas SPA, Gym dan Fitness

\section{Lantai 2}

Balkon sekalian untuk parkir motor dan void yang dapat digunakan untuk keluasan pada kolam renang di lamtai 1.

\section{Gambar 13: Zonifikasi Vertikal}

Sumber : Analisis Penulis, 2018

Konsep fasade atau tampilan bangunan berasal dari ide aplikasi geometri 3D pada building cover yang menggunakan teori combined metaphors dengan bentuk persegi, elips berujung runcing, dan lingkaran. Ketiga bentuk ini dikombinasikan membentuk motif batik kawung, yang diletakkan di sekeliling bangunan. Sedangkan pada side cover dan lattice cover menggunakan bahan yaitu aluminium, PTFE berlapis teflon, eter, dan fibrelux . Ide ini digunakan sebagai cara untuk mencari bentuk kebaruan yang akan dikombinasikan dengan Tirtomoyo yang merupakan memori di masa lalu.
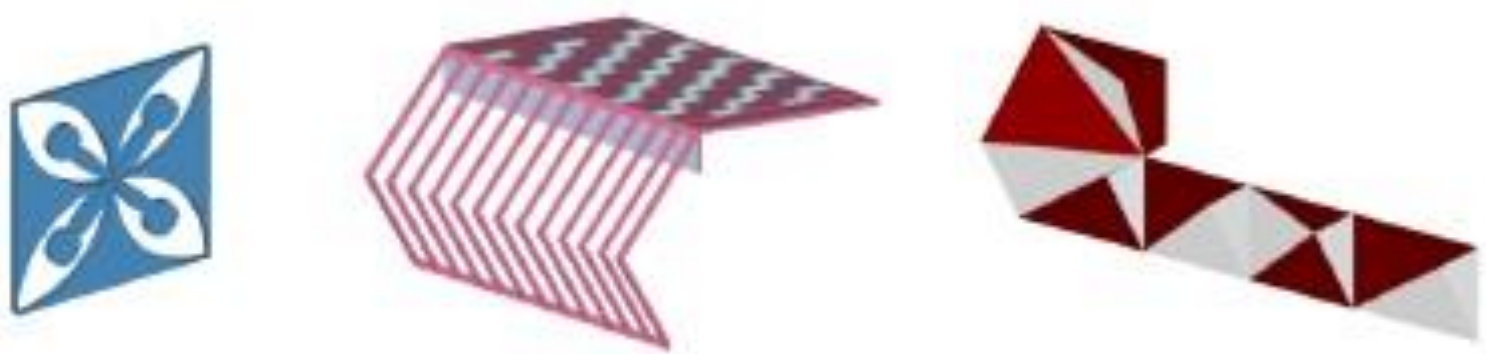

Gambar 14: Motif Kawung dan Disain Cover Bangunan 


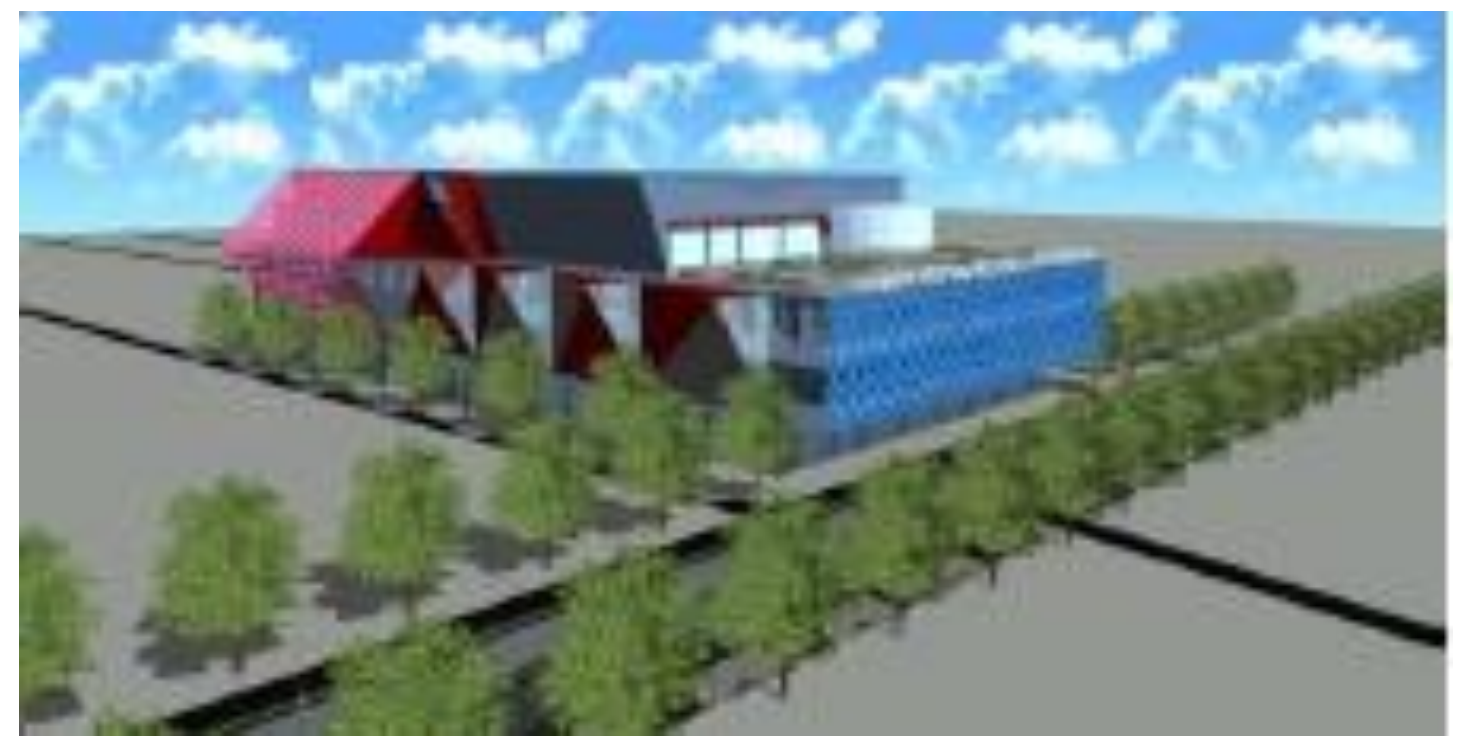

Gambar 15. Bentuk Tampilan Bangunan /Fasade

Pada entrance terdapat gambar berupa foto Kolam Renang Tirtomoyo Jebres saat digunakan sebagai tempat PON. Gambar ini tersedia di sepanjang selasar dari entrance menuju ke kolam renang. Perbaikan material kolam renang dan pemberian pagar batasan antara kolam dewasa dan anak. Tribun pengunjung tidak mengalami banyak perubahan, hanya berupa penggabungan tribun agar dapat memuat lebih banyak pengunjung.

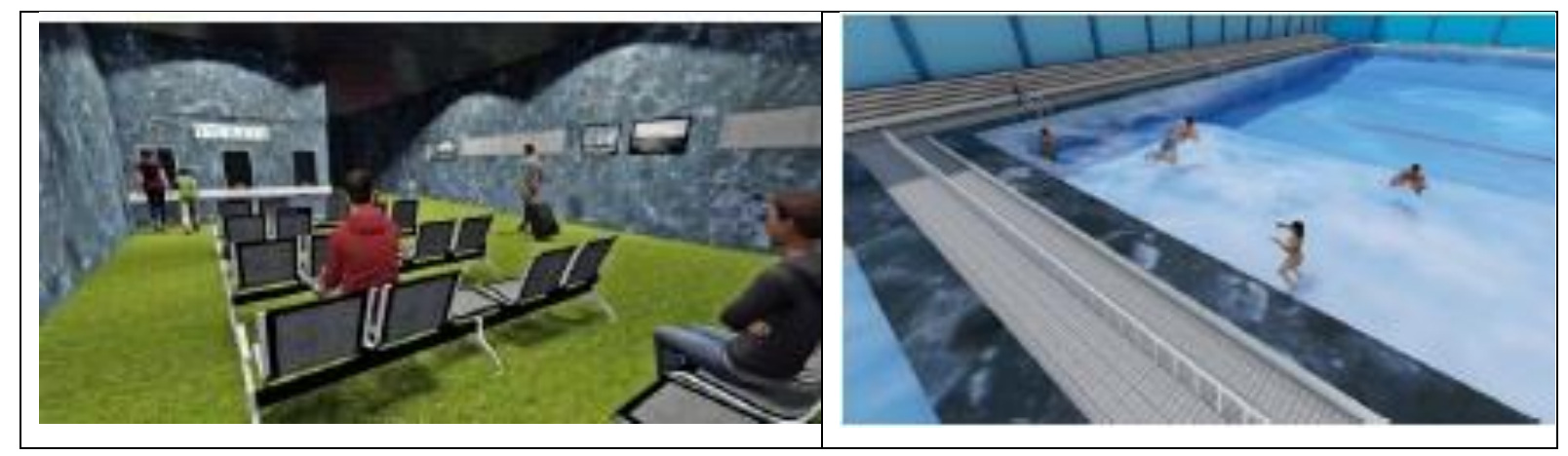

Gambar 16. Tampilan pada Hall depan dengan foto-foto peristiwa PON tahun 1948 pada dindingnya dan perbaikan kolam renang dan tribun 


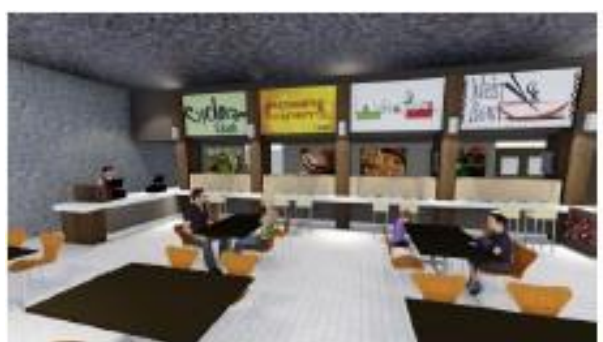

5.3 Foodcourt

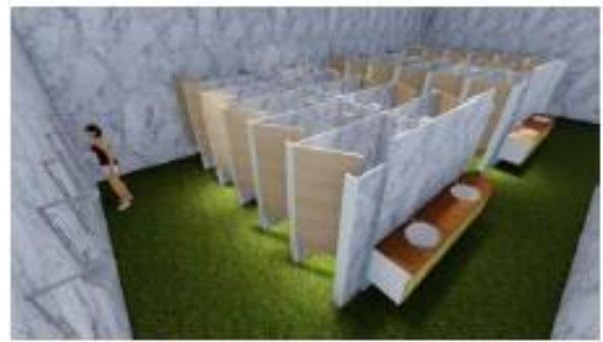

5.5 Ruang Bilas

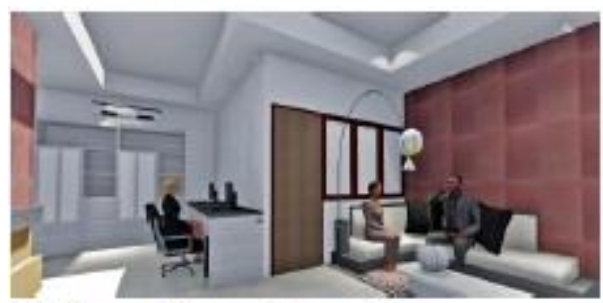

5.7 Ruang Kantor Pengelola

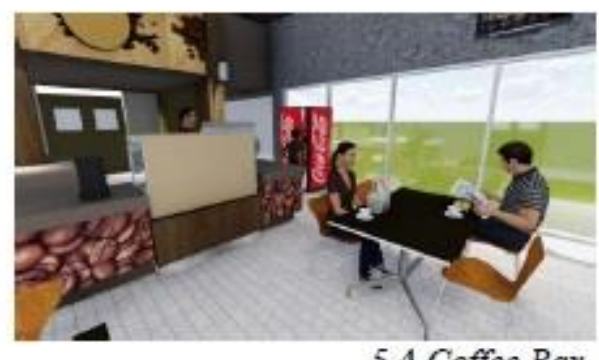

5.4 Coffee Bar

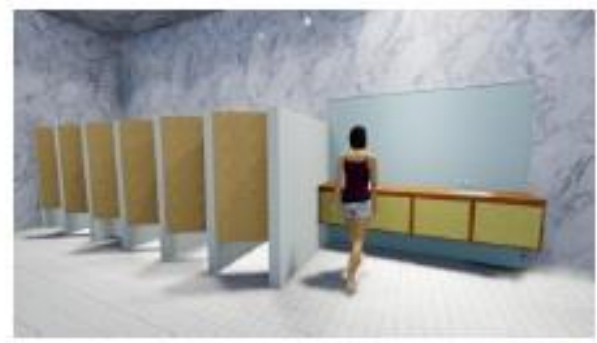

5.6 Toilet

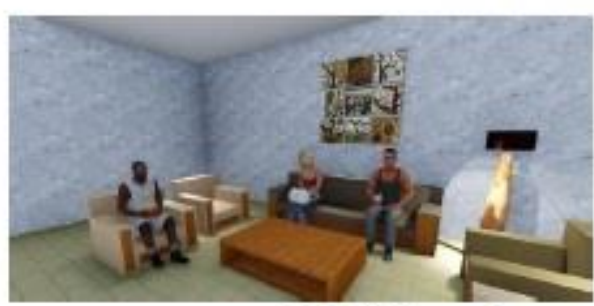

5.8 Wellness Lounge

Gambar 17. Interior

Tersedia ruang gym sebanyak empat ruangan dengan tambahan dua ruangan senam. Untuk merealisasikan wellness center, disediakan juga ruang sauna, spa, dan hydrotherapy area.

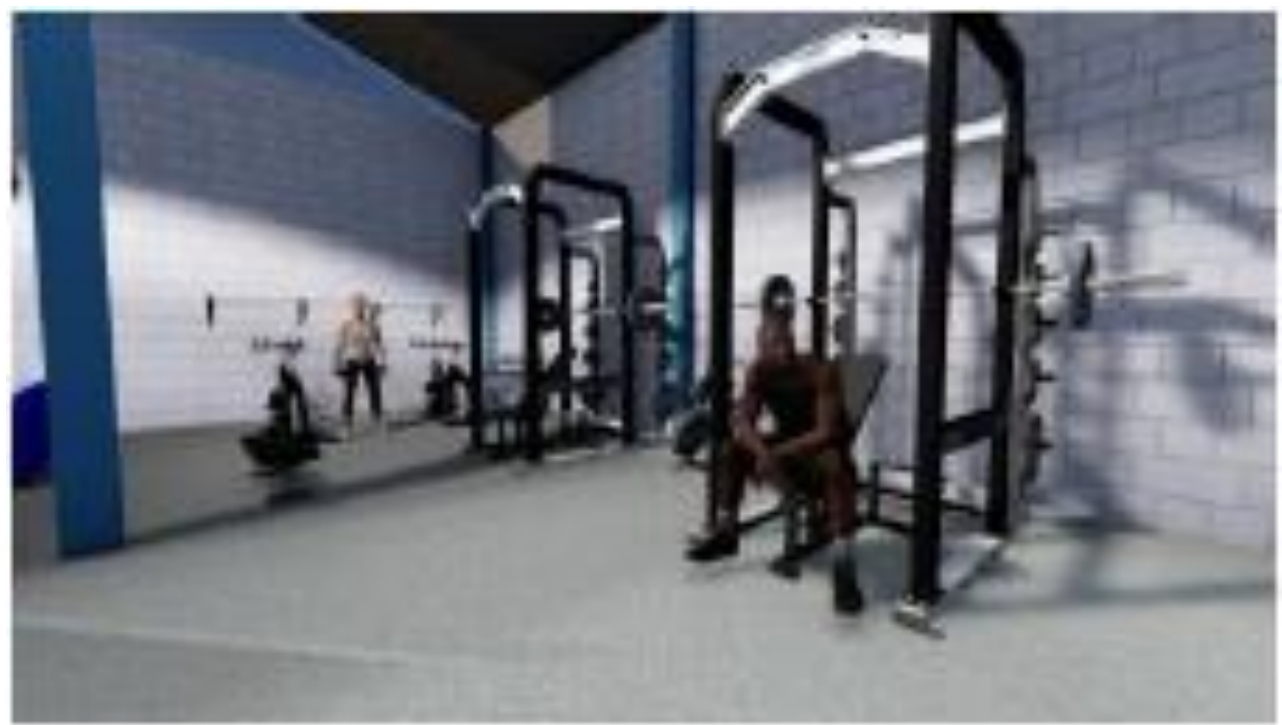

Gambar 128. Ruang untuk Gym 


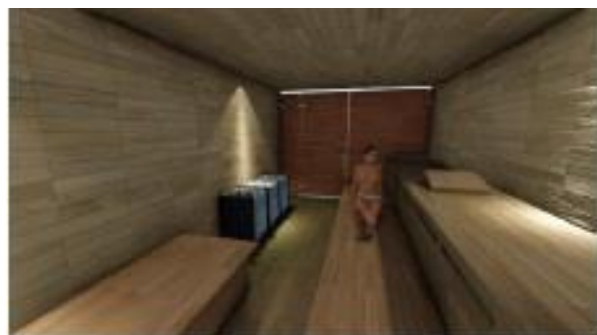

5.10 Sauna

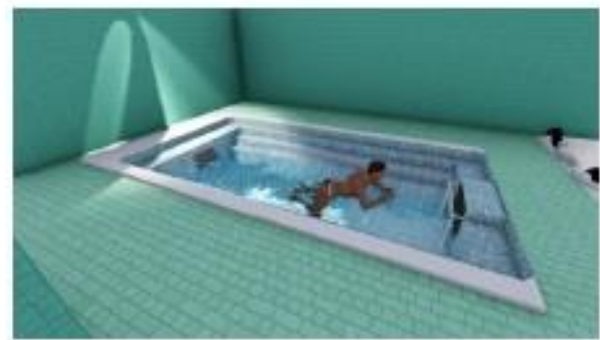

5.12 Endless Pool

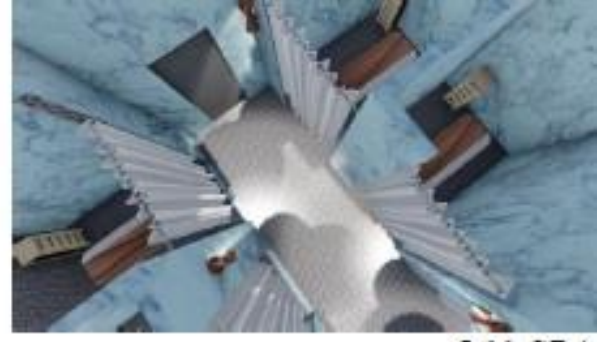

$5.11 S P A$

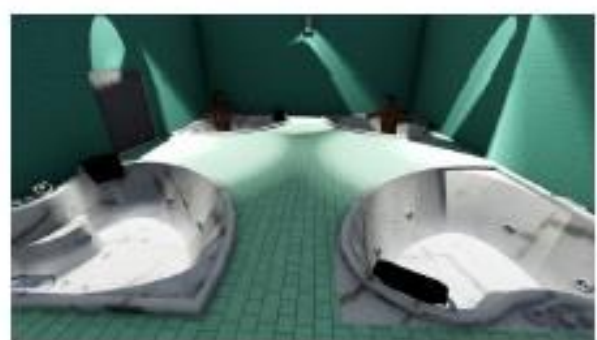

5.13 Whirlpool

Gambar 139. Ruang-ruang Fasilitas SPA

\section{SIMPULAN}

Revitalisasi Tirtomoyo sebagai arena olah raga dan Wellness Center di Surakarta dengan menggunakan konsep dekonstruksi merupakan suatu saran alternatif agar dapat menghidupkan kembali bangunan Kolam Renang Tirtomoyo Jebres dengan lebih baik daripada yang sedang berjalan saat ini. Dengan perubahan desain interior maupun eksterior dan penambahan fasilitas penunjang kebugaran diharapkan dapat menjadi masukan bagi pengembangan Kota Surakarta di masa mendatang.

\section{DAFTAR PUSTAKA}

[1] SFU. (2014, January 1). The 7 Dimensions of Wellness. Retrieved from Simon Fraser University Student Services Health \& Counselling: http://www.sfu.ca/students/health/resources/wellness/wheel.html

[2] Menpora. (2005). Undang-Undang Republik Indonesia Nomor 3 Tentang Sistem Keolahragaan. Jakarta: Republik Indonesia

[3] Pasireurih, K. (2018, March 1). Pengertian Olahraga Secara Umum. Retrieved from Karang Taruna Indonesia: http://katarpasireurih.blogspot.co.id/2014/05/pengertian-olahraga-secaraumum.html

[4] Wikipedia. (2018, March 1). Kolam Renang. Retrieved from Wikipedia Ensiklopedia Bebas: https://id.wikipedia.org/wiki/Kolam_renang

[5] Finika Nurasih, 2016, Apa itu Konservasi, https://finifio.wordpress.com/2016/06/04/

[6] 2018, http://www.tschumi.com/projects/12/ 2018.

[7] Noor Zakiy Mubarrok ,2016, 'Displacement', Kriteria Dekonstruksi Peter Eisenman, Jurnal Arsitektur KOMPOSISI, Volume 11, Nomor 3, April 2016

[8] ArchDaily. (2016, July 25). Swimming Pool Allmendli / illiz Architektur. Retrieved from arch daily: the world's most visited architecture website: https://www.archdaily.com/791888/swimming-pool-allmendli-illiz-architektur

[9] Hawkins \Brown. (2016, March 3). City of London Freemen's School, Swimming Pool. Retrieved from Hawkins \Brown Architects LLP: https://www.hawkinsbrown.com/projects/city-of-londonfreemens-school-swimming-pool 2018, https://libeskind.com/work/royal-ontario-museum/ 2018. Tirtomoyo Surakarta, http:// geogle map. 
[12].[13].

[14].[8]___ 2018, Royal Ontario Museum , https://libeskind.com/work/royal-ontario-museum/, 2018

[15]._[11] [16]. [12] , 2015, Walt Disney Concert Hall, https://www.archute.com/2015/09/28 .2018, Tirtomoyo Surakarta, https://www.google.co.id/maps 